T. Bohush

Research supervisor: E.O. Sevostianov, Doctor of Physics and Mathematics, Zhytomyr Ivan Franko State University

Language tutor: D.O.Volnytska

\title{
COUNTABLE AND UNCOUNTABLE SETS
}

The appearance and development of set theory is connected with the research of infinite sets, which were founded by a famous German mathematician Georg Cantor (1845-1918). The concept of set has a remarkable impact on Mathematics in general, so a lot of scientists worked with sets and included them in many sections of their textbooks. [2]

There is a variety of sets in Mathematics. You can talk about the set of polyhedron faces, points on the line, the set of natural numbers and so on. All sets consist of elements, but there are sets that do not contain any elements (the set of the equation roots), they are called empty sets.

Sets A and B are called equipotent, if they are empty, or there is a bijection between them, that means that each element of the set $\mathrm{A}$ corresponds to the one and the only one element of the set $\mathrm{B}$, and vice versa. [1]

The set $\mathrm{A}$ that is equipotent to the set $\mathrm{N}$ of natural numbers is called countable set, in other words, the countable set $\mathrm{A}$ is such a set, where all elements can be numbered by natural numbers $1,2,3, \ldots . .[2]$

Some examples of countable sets are:

- The set of all integer numbers

- The set of all even positive numbers

- The set of degrees of $2\left(2,4,8, \ldots, 2^{\mathrm{n}}, \ldots\right)$

- The set $\mathrm{P}=\left\{1, \frac{1}{2}, \frac{1}{3}, \ldots, \frac{1}{n}, \ldots\right\}$

- The set of all rational numbers [1,3]

The main properties of countable sets are:

- Any subset of countable set is either finite or countable set.

- The sum of any finite or countable set of countable sets is also countable set.

- From any infinite set we can allocate finite or countable subset in such a way that the set which is remained will be equivalent to the original one.

- If $A=\left(a_{1}, \ldots, a_{k}, \ldots\right)$ and $B=\left(b_{1}, \ldots, b_{n}\right)$ are countable sets, then the set of all pairs $\left(a_{k}, b_{n}\right)(k, n=1,2,3, \ldots)$ is a countable set.

- Any infinite set contains a countable subset. [1]

The fact of the existence of sets that are not countable (uncountable sets), was established by Georg Cantor with the help of his diagonal method, which later became of fundamental importance in various areas of Mathematics.

The set of all real numbers from the interval $(0,1)$ is uncountable set (the proof is based on the diagonal method). 
Any set that is equipotent to all real numbers on the interval $(0.1)$ is called a path or set of a continuum power.

The main properties of uncountable sets are:

- The set of all sequences composed of a series of natural numbers, has a continuum power or is an uncountable set.

- Finite or countable combining of countable sets has a continuum power.

- If $\mathrm{M}$ is an uncountable set, and $\mathrm{A}$ is a finite or countable subset of $\mathrm{M}$, then the set $\mathrm{M} \backslash \mathrm{A}$ and the set $\mathrm{M}$ are equipotent.

- Set $\beta(A)$ of all subsets of a countable set $A$ has a continuum power. [1,3]

Analyzing the above, we can conclude that the achievements in the study of set theory are quite essential and this is an important contribution to modern Mathematics.

\section{LITERATURE}

1. Колмогоров А. Н., Фомин СВ. Элементы теории функций и функционального анализа. - 7-е изд. - М.: ФИЗМАТЛИТ, 2004. - 572 с.

2. Лузин Н.Н. Теория функций действительного переменного.(на украинском языке) - К.: «РАДЯНСЬКА ШКОЛА», 1953. - 308 с.

3. Коваленко С.І. Вища математика. Посібник. - Харків, 2002. 